\title{
Sentinel lymph node detection in patients with cervical cancer in a public hospital in Guatemala
}

\author{
Erick Estuardo Estrada, Guatemala City 0101, Guatemala
}

Sentinel lymph node biopsy has been widely studied in a number of cancers. ${ }^{1}$ In cervical cancer, this technique has been shown to be safe and feasible. There is still some debate on the role of sentinel lymph node biopsy in cervical cancer; however, most studies have shown that such a procedure offers significant advantages over complete lymphadenectomy. ${ }^{2}$ Blue dye is used as a valid alternative in many centers, due to the lower cost. We conducted a study to evaluate the feasibility of sentinel lymph node detection in patients with cervical cancer using the low-cost methylene blue dye.

Patients with 2009 International Federationof Gynecology and Obstetrics (FIGO) stage IA2 to IB2 cervical cancer who underwent abdominal radical hysterectomy and pelvic lymphadenectomy were enrolled. Methylene blue was injected, $1 \mathrm{~mL}$ in depth and $1 \mathrm{~mL}$ on the surface of the cervix at 3 o'clock and 9 o'clock.(figure 1) The result of the sentinel lymph node biopsy

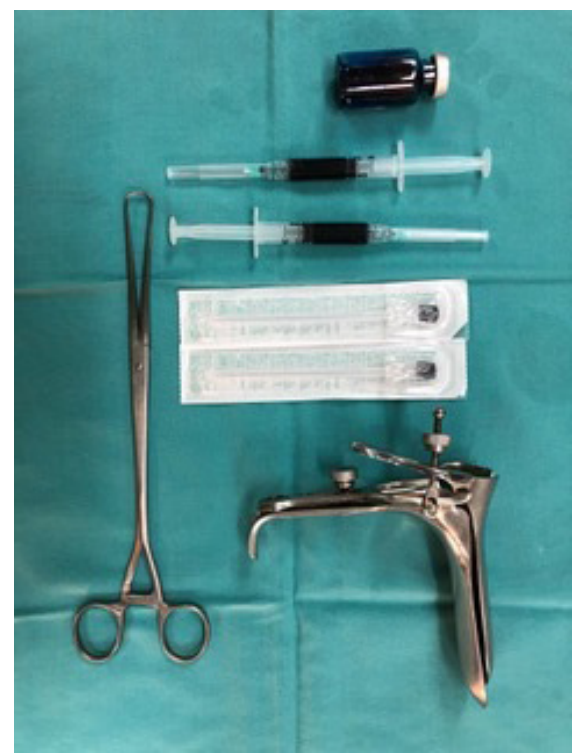

Figure 1 Required equipment and materials for sentinel lymph node detection. Photograph reproduced with permission of Dr Julio Lau.

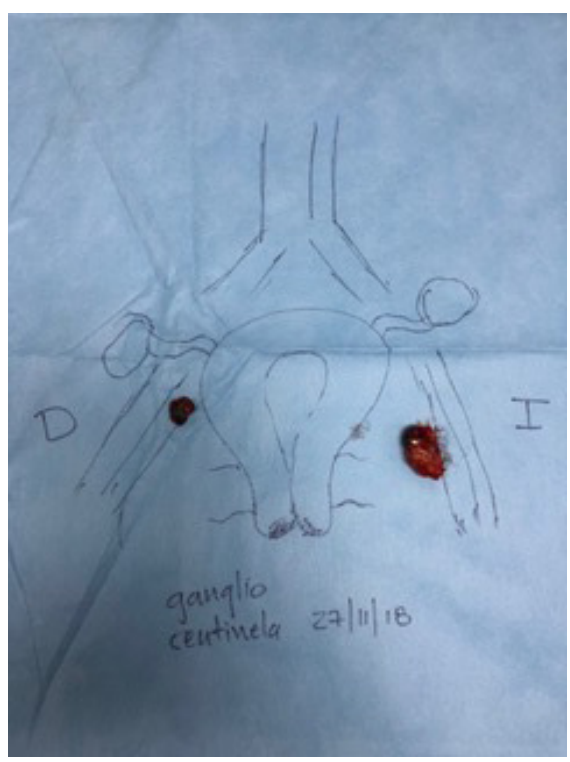

Figure 2 Example of sentinel lymph node detection and location. Photograph reproduced with permission of Dr Julio Lau.

was obtained using ultrastaging; cytokeratin immunohistochemical staining was performed.

We enrolled 61 patients during a 60-month period and sentinel lymph node mapping was performed. All patients underwent a complete lymphadenectomy. The median patient age was 45 years (range 29-77). The median body mass index was $22.42 \mathrm{~kg} / \mathrm{m}^{2}$ (range 18-29). The bilateral detection rate was $85.2 \%$ and the unilateral sentinel lymph node detection rate was $89 \%(95 \% \mathrm{Cl} 82.3$ to 91.6$)$. The specificity was $100 \%$ and sensitivity and negative predictive value were $90 \%$ and $97 \%$, respectively. Sentinel lymph nodes were identified in the obturator, external iliac, and internal iliac areas in 50\%, 31.7\%, and $18.3 \%$ of cases, respectively.(figure 2) No sentinel lymph nodes were found in the common iliac region. The mean number of sentinel lymph nodes per patient was 2.34 , and $14 \%$ were positive for metastasis.
Blue dye cervical injection is a "lowcost", safe, and feasible procedure to detect sentinel lymph nodes in carcinoma of the cervix. Other tracers, such as indocyanine green, are widely used in gynecological oncology, but with a higher cost and the need for a dedicated optical filter. In our low resource setting, we consider that sentinel lymph node mapping is feasible with the use of blue dye.

\section{Correspondence to Dr Erick Estuardo Estrada,} Gynecology and Obstetrics, Hospital General San Juan de Dios, Guatemala City 0101, Guatemala; mderickestrada@yahoo.com

Twitter Erick Estuardo Estrada @mderickestrada Acknowledgements Dr Julio Lau has served as a reviewer for this study and the photographs used in this report belong to him. We would also like to thank $\mathrm{H}$ Andrade, M Justiniano, LG Cifuentes, ER Andrino, CA Reyes, J Lau de la Vega for their valuble contribution towards this paper.

Funding The authors have not declared a specific grant for this research from any funding agency in the public, commercial or not-for-profit sectors.

Editor's note This paper will feature in a special issue on sentinel lymph node mapping in 2020 .

Competing interests None declared.

Patient consent for publication Not required.

Provenance and peer review Commissioned; externally peer reviewed.

(C) IGCS and ESGO 2020. No commercial re-use. See rights and permissions. Published by BMJ.

$$
\text { Check for updates }
$$

To cite Estrada EE. Int J Gynecol Cancer 2020;30:406.

Accepted 10 0ctober 2019

Published Online First 8 December 2019

Int J Gynecol Cancer 2020;30:406.

doi:10.1136/ijgc-2019-000839

\section{REFERENCES}

1 Diab Y. Sentinel lymph nodes mapping in cervical cancer a comprehensive review. Int J Gynecol Cancer 2017;27:154-8.

2 Holman LL, Levenback CF, Frumovitz M. Sentinel lymph node evaluation in women with cervical cancer. J Minim Invasive Gynecol 2014;21:540-5. 